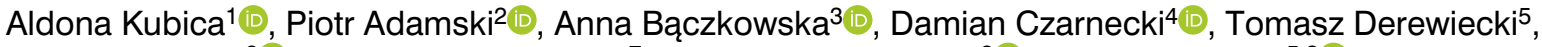
Rafał Donderski6(i), Elżbieta Grzechowiak ${ }^{7}$, Małgorzata Jasiewicz²®, Andrzej Kleinrok ${ }^{5,8}$,

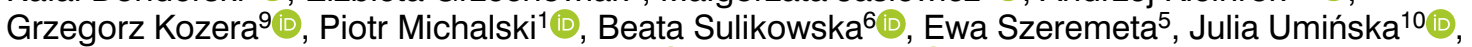
Katarzyna Ulaszewska ${ }^{7}$, Marcin Ziółkowski ${ }^{4}$, Jacek Kubica ${ }^{2}$ (])

${ }^{1}$ Department of Health Promotion, Collegium Medicum, Nicolaus Copernicus University, Bydgoszcz, Poland

2Department of Cardiology and Internal Medicine, Collegium Medicum, Nicolaus Copernicus University, Bydgoszcz, Poland

3English Language and Theoretical Linguistics Division, Institute of English and American Studies, University of Gdańsk, Poland

${ }^{4}$ Department of Preventive Nursing, Collegium Medicum, Nicolaus Copernicus University, Bydgoszcz, Poland

${ }^{5}$ Department of Cardiology, The Pope John Paul II Hospital in Zamość

${ }^{6}$ Department of Nephrology, Hypertension and Internal Diseases, Collegium Medicum, Nicolaus Copernicus University, Bydgoszcz, Poland

${ }^{7}$ Department of Neurology, Collegium Medicum, Nicolaus Copernicus University, Bydgoszcz, Poland

8 University of Information Technology and Management in Rzeszów, Poland

${ }^{9}$ Medical University of Gdańsk, Poland

${ }^{10}$ Department of Geriatrics, Collegium Medicum, Nicolaus Copernicus University, Bydgoszcz, Poland

\title{
The rationale for Multilevel Educational and Motivational Intervention in Patients after Myocardial Infarction (MEDMOTION) project is to support multicentre randomized clinical trial Evaluating Safety and Efficacy of Two Ticagrelor-based De-escalation Antiplatelet Strategies in Acute Coronary Syndrome (ELECTRA - SIRIO 2)
}

\section{Corresponding author:}

Aldona Kubica, Department of Health Promotion, Collegium Medicum, Nicolaus Copernicus University, Bydgoszcz, Poland,

e-mail: aldona.kubica@gmail.com

\begin{abstract}
The Multilevel Educational and Motivational Intervention in Patients after Myocardial Infarction (MEDMOTION) project will be adopted to support adherence to the study treatment in the Evaluation Safety and Efficacy of Two Ticagrelor-based De-escalation Antiplatelet Strategies in Acute Coronary Syndrome (ELECTRA-SIRIO 2) a randomized clinical trial.

A prespecified sub-analysis of the ELECTRA-SIRIO 2 trial will be performed to evaluate the impact of the results of MEDMOTION diagnostic questionnaires on the clinical outcomes.

The study population will comprise of 4,500 patients consecutively admitted to the study centres due to acute coronary syndrome. The MEDMOTION project involves the following interventions: patients' education, motivation, reminding to take medications and to attend consecutive medical appointments. Dedicated questionnaires will be applied to diagnose study participants with regard to their readiness for discharge from the hospital at the end of initial hospitalization, the risk of non-adherence to the medication at the end of $3^{\text {rd }}$ and $12^{\text {th }}$ month of follow up, and the functioning in disease at the end of $3^{\text {rd }}$ and $12^{\text {th }}$ month of follow up. The primary safety composite endpoint of this study is type 2,3 or 5 bleeding according to the BARC criteria, occurring during the first 12 months after ACS. The primary efficacy endpoint is the composite of death from any cause, the first nonfatal $\mathrm{Ml}$, or the first nonfatal stroke. The key secondary endpoint, net clinical effect, was defined as the composite of death from any cause, a nonfatal Ml or a nonfatal stroke, and the first occurrence of BARC type 2, 3, or 5 bleeding.
\end{abstract}


Medical Research Journal 2020 Volume 5, Number 4, 244-249 DOI: $10.5603 / M R J . a 2020.0043$ Copyright (C) 2020 Via Medica ISSN 2451-2591
Concluding, it is expected that the comprehensive approach designed in the MEDMOTION project, including use of diagnostic questionnaires, will significantly contribute to obtaining a high level of adherence to medication and improving clinical outcomes in the ELECTRA-SIRIO 2 trial.

Key words: acute coronary syndrome, adherence to medication, functioning in chronic illness, ticagrelor, antiplatelet treatment

Med Res J 2020; 5 (4): 244-249

\section{Background}

The World Health Organization (WHO) defines "adherence" as "the extent to which a person's behaviour including taking medication, following a diet, and/or executing lifestyle changes, corresponds with agreed recommendations from a health care provider" [1]. According to the Food and Drug Administration data, from 30 to $50 \%$ of patients do not exactly adhere to recommendations received from their healthcare providers, which significantly increases the risk of unfavourable clinical outcome [2-5, 22, 24-26]. The enhancement of medication adherence is usually accompanied by the elimination of unfavourable dietary habits and improvement in physical activity [6-10, 20]. Good adherence to medication is a pivotal factor for reliable evaluation of new drugs and new treatment strategies tested in clinical trials [37]. Therefore, the Multilevel Educational and Motivational Intervention in Patients After Myocardial Infarction (MEDMOTION) project will be adopted to support adherence to the study treatment in the Evaluation of Safety and Efficacy of Two Ticagrelor-based De-escalation Antiplatelet Strategies in Acute Coronary Syndrome (ELECTRA-SIRIO 2) a randomized clinical trial.

The ELECTRA-SIRIO 2 trial aims to evaluate the safety and efficacy of ticagrelor dose reduction with or without the continuation of aspirin versus DAPT with standard-dose ticagrelor, in reducing clinically relevant bleeding and in maintaining anti-ischaemic efficacy in ACS patients. The trial was designed as a phase III, randomised, multicentre, double-blind, investigator-initiated clinical study with a 12-month follow-up. Up to 35 centres are expected to participate in the trial. The study population will comprise of 4,500 patients consecutively admitted to the study centres due to ACS, including patients with ST-elevation myocardial infarction, non-ST-elevation myocardial infarction and unstable angina [35]. All study participants will be randomized during hospitalization for the index ACS into one of three arms: low-dose ticagrelor with aspirin group, low-dose ticagrelor with the placebo group, and the control arm treated with standard-dose ticagrelor with aspirin. All patients enrolled into this trial are expected to undergo 5 out-patient follow-up visits $(1,3,6,9$ and 12 months after the index ACS), during which they will undergo the assessment of the study endpoints and careful evaluation of adherence to the study treatment based on tablets counting at follow-up visits. Moreover, in line with the MEDMOTION project, dedicated questionnaires will be applied to diagnose study participants with regard to their readiness for discharge from the hospital at the end of initial hospitalization, the risk of non-adherence to the medication at the end of $3^{\text {rd }}$ and $12^{\text {th }}$ month of follow up, and the functioning in disease at the end of $3^{\text {rd }}$ and $12^{\text {th }}$ month of follow up. The primary safety composite endpoint of this study is type 2, 3 or 5 bleeding according to the BARC criteria, occurring during the first 12 months after ACS. The primary efficacy endpoint is the composite of death from any cause, the first nonfatal MI, or the first nonfatal stroke. The key secondary endpoint, net clinical effect, was defined as the composite of death from any cause, a nonfatal MI or a nonfatal stroke, and the first occurrence of BARC type 2, 3, or 5 bleeding.

A prespecified sub-analysis of the ELECTRA-SIRIO 2 trial will be performed to evaluate the impact of the results of MEDMOTION diagnostic questionnaires on the clinical outcomes.

\section{Methods}

\section{Project design}

The MEDMOTION project involves the following interventions: patients' education, motivation, reminding to take medications and to attend consecutive medical appointments. Furthermore, questionnaire-based diagnoses of readiness to discharge from hospital, adherence to treatment, and functioning in chronic disease are essential parts of this project [38].

\section{MEDMOTION interventions}

\section{Patients' education}

The educational interventions are aimed to improve the knowledge and practical skills of both patients after ACS and their cohabitating family members [14, $40,43]$. It is assumed that individualized, complex education started during hospitalisation and continued after discharge, which would include explaining the pathophysiology, symptoms and prevention of coronary 
artery disease, elucidating goals and potential benefits of treatment, as well as highlighting the risk of premature termination of therapy, with the use of additional methods helping patients to remember the treatment schedule, will enhance adherence to treatment [44].

The education mentioned above will be standardized, i.e. based on a series of brochures Reach for Health developed for the MEDMOTION project, and at the same time individualized as a set of brochures in one workbook will be selected individually depending on patients' needs.

The following Reach for Health brochures have been included in the protocol of ELECTRA - SIRIO 2 trial:

1. Reach for knowledge - coronary artery disease, myocardial infarction by Kubica A and Umińska JM

2. Woman, reach for health by Jasiewicz M

3. Reach for medication Umińska JM and Kubica J

4. Reach for knowledge - hypertension by Sulikowska $\mathrm{B}$, Donderski R

5. Reach for knowledge - diabetes mellitus by Umińska JM

6. Reach for knowledge about nutrition by Michalski P

7. Reach for physical activity by Kleinrok A and Derewiecki T

8. Do not reach for a cigarette by Czarnecki D, Ziółkowski M.

The series of brochures Reach for Health is supplemented by a patient self-control diary.

Apart from the brochures included into ELECTRA - SIRIO 2 trial protocol, two additional brochures were developed for the MEDMOTION project:

1. Reach for knowledge - stroke by Ulaszewska K, Grzechowiak E, and Kozera G

2. Reach for physical activity after stroke by Szeremeta $\mathrm{E}$

All brochures have a similar structure, starting with a brief chapter entitled: Do you know that ...? - containing the most interesting facts designed to grab the reader's attention. The main part provides the patient with important information in an accessible, illustrated form. The brochure ends with take-home messages and answers to common questions.

Verbal education of patients related to the content of brochures will be started during the initial hospitalization period and continued during five scheduled follow-up visits. A set of individually selected brochures will be given to the patient during the initial hospitalization.

\section{Patients' motivation}

Patients' education will be supported by motivational interventions [41]. The motivational interview will be conducted by healthcare staff during the initial hospitalization period and follow-up visits. The motivational interview is a widely used, scientifically tested and clinically relevant method of patient counselling developed by Miller and Rollnick [49,50]. Effective application of both in-hospital motivational interview as well as post-discharge behavioural interventions (telephone-based, text messages) for cardiovascular prevention have been already reported [51-57]. In essence, the motivational interview promotes partnership-oriented counselling interventions of healthcare staff with the patient. Change elicitation results from evoking the patient's intrinsic motivation for behavioural change by drawing on personally meaningful goals. The patient's autonomy is fully respected, which entails shifting the decision to implement behavioural changes and the responsibility of change implementation outcomes from the medical staff to the patient. The motivational interview should be conducted by medical staff with empathy, emphasizing the discrepancy between the current state and the patients' future well-being, 'rolling' with patients' resistance to change and bolstering their self-efficacy and self-regulation [58].

The key assumptions of Motivational Interview thus comprise, firstly, a non-judgemental approach to the patient's perspective and active interest to understand how the situation is perceived through the patient's eyes (active empathy). Secondly, it involves focusing on the gap existing between the patient's current and the expected behavioural patterns (develop discrepancy) to identify the starting point for future change implementation, which, importantly, is to be initiated by the patient rather than the therapist. The fact that it is the patient who is to identify the need for change should minimize the chance of an argument and resistance (avoid argument). Once the patient agrees to implement behavioural changes, it can be expected that the patient will have to deal with several ambivalent periods that will need assistance and problem-solving measures (rolling with resistance). The main role of the therapist's in such periods will be to reinforce the patient's capacity of self-direction, i.e. the conviction that he can deal with the problems himself (self-efficacy). Given the adequate therapeutic conditions, a patient is expected to evolve and enhance his health-oriented behavioural patterns with the therapist's gentle guidance and reinforcement of proper changes. The main idea of motivational interviewing is thus not to coerce and control but to guide and support.

\section{Reminding patients to take medications and attend consecutive medical appointments}

In order to increase protocol adherence and patient retention, a convenient, intuitive data collection interface available for patients as an online and mobile platform will be used in the MEDMOTION project. The main features of this supporting software are to inform 
and guide patients with clear instructions managing the visit calendar: reminders about the date and place of the control visit; information on what to bring to the visit and also to make an unplanned visit in case of urgent necessity. The system will also provide support to the patient with every day reminding of the need to regularly take drugs and it will provide patients with relevant educational content. Moreover, a patient diary, allowing him to report any adverse events will be available.

\section{MEDMOTION questionnaire-based diagnoses}

\section{Diagnosis of readiness to discharge from hospital}

The Readiness for Hospital Discharge after Myocardial Infarction Scale (RHD-MIS) was designed for subjects after myocardial infarction $[21,39,46,48]$. The questionnaire consists of 23 questions: the subjective assessment of patients' knowledge includes 7 items, patient's expectations comprise 9 items, and 7 items are dedicated to the objective assessment of patients' knowledge. The RHD-MIS was validated in patients recovered for ACS and treated with the percutaneous coronary intervention. The internal consistency of the entire questionnaire was confirmed by the alpha-Cronbach coefficient of 0.789 . The RHD-MIS fulfilled the assumption of factor analysis: the determinant of the correlation matrix was 0.001 , Kaiser-Mayer-Olkin (K-M-O) statistic was 0.723 , and the Bartlett' test of sphericity was statistically significant. The analysis of the internal consistency of the three areas confirmed the rightness of distinguishing three subscales [48].

\section{Diagnosis of adherence to treatment}

Apart from the intention-to-treat analysis, the on-treatment analysis of the trial outcome is planned, therefore accurate evaluation of adherence in necessary. There is no gold standard, nor a universal tool which could evaluate the level of adherence; therefore, direct (tablets counting at follow-up visits) and indirect method (the Adherence in Chronic Diseases Scale - ACDS) will be applied in the ELECTRA-SIRIO 2 trial.

The ACDS was validated and subsequently applied to patients after myocardial infarction [23]. It was designed to identify patients of a high risk of low adherence, as well as beliefs, barriers and behaviour related to medication adherence [44]. The internal consistency of the ACDS final 7 items version was assessed using Cronbach's alpha coefficient, and the value of 0.752 confirmed high reliability and homogeneity of the questionnaire. The determinant of the correlation matrix was 0.211 , the value of $\mathrm{K}-\mathrm{M}-\mathrm{O}$ statistic was 0.848 and Bartlett's test of sphericity was statistically significant [19]. The ACDS indicating subjects of the high risk of low adherence has the potential to improve patient - a health care professional communication and relationship, which are the key points providing higher adherence to the specific therapy.

\section{Diagnosis of functioning in chronic disease}

The Functioning in Chronic Illness Scale (FCIS) has been designed to evaluate the impact of the disease on the patient, the patients' impact on the disease and the impact of the disease on patients' attitudes [42]. It is the first and only available tool allowing a comprehensive assessment of physical and mental functioning dedicated to patients with chronic diseases. The FCIS was validated in patients with coronary artery disease treated with PCl. The questionnaire consists of 24 questions and it is divided into three subscales. The value of the a-Cronbach coefficient for the entire questionnaire was 0.855 indicating that the questionnaire is reliable and homogenous. The value of the determinant of the correlation matrix was $0.001, \mathrm{~K}-\mathrm{M}-\mathrm{O}$ parameter was 0.843 and the Bartlett' test of sphericity was statistically significant [42]. The assessment of various aspects of patients' functioning with FCIS allows diagnosing deficit areas to implement appropriate therapeutic and educational interventions.

\section{Discussion}

Poor adherence to medication is known to deteriorate clinical outcome in patients after ACS $[13,27,28,32,34]$. Ensuring good adherence is also a critical issue in randomized clinical trials evaluating treatment strategies, as the intention-to-treat analysis, i.e. with the inclusion of all patients according to the randomly assigned trial group, irrespective of the actual treatment received, is a widely accepted method for such kind of studies [36]. Poor adherence to the evaluated treatment may lead to a serious result bias. To estimate this bias, the on-treatment analysis should supplement the results; however, to perform such an analysis knowledge of actual adherence recorded for each patient is essential $[11,12]$. Therefore, to ensure the highest quality and reliability of results the MEDMOTION project was included in the ELECTRA-SIRIO 2 trial. Patients' self-reported drug intake is an unreliable method of adherence evaluation [12, 29-32]; therefore, tablets counting at follow-up visits will additionally be applied.

Diverse interventions aimed to ameliorate the adherence to medication planned in the MEDMOTION project, including education, motivation, and "reminders" [15, $16,47]$, will be supported by a comprehensive, multistage assessment of patients, which should improve 
the quality of medical care by personalizing these interventions in patients enrolled into the ELECTRA-SIRIO 2 trial $[17,18,33]$. The Readiness for Hospital Discharge after Myocardial Infarction Scale (RHD-MIS) [48] was designed for in-hospital evaluation, while the Adherence in Chronic Diseases Scale (ACDS) $[19,23]$ and the Functioning in Chronic Illness Scale (FCIS) [42] was meant for examination during follow-up visits. It was developed as a tool aimed to improve the quality of the discharge process, including additional personalized education and motivation. All the presented tools were expected to reflect the effectiveness of different aspects of patient-medical staff collaboration and were tested in patients with coronary artery disease after ACS treated with PCl [19, 42, 45, 46].

Concluding, it is expected that the comprehensive approach designed in the MEDMOTION project, including use of diagnostic questionnaires, will significantly contribute to obtaining a high level of adherence to medication and improving clinical outcomes in the ELECTRA-SIRIO 2 trial.

\section{Funding: This research received financial support from the Medical Research Agency, Poland, through Project no. 2019/ABM/01/00009.}

\section{References}

1. Barrett. Tx. World Health Organization. Adherence to long-term therapies: evidence for action. http://www.who.int/chp/knowledge/publications/adherence full_report.pd.

2. Simpson SH, Eurich DT, Majumdar SR, et al. A meta-analysis of the association between adherence to drug therapy and mortality. BMJ. 2006; 333(7557): 15, doi: 10.1136/bmj.38875.675486.55, indexed in Pubmed: 16790458.

3. Kubica J, Adamski P, Buszko K, et al. Rationale and Design of the Effectiveness of LowEr maintenanCe dose of TicagRelor early After myocardial infarction (ELECTRA) pilot study. Eur Heart J Cardiovasc Pharmacother. 2018; 4(3): 152-157, doi: 10.1093/ehjcvp/pvx032, indexed in Pubmed: 29040445.

4. Winter MP, Grove EL, De Caterina R, et al. Advocating cardiovascular precision medicine with P2Y12 receptor inhibitors. Eur Heart J Cardiovasc Pharmacother. 2017; 3(4): 221-234, doi: 10.1093/ehjcvp/pvw044, indexed in Pubmed: 28204303

5. Winter MP, Koziński M, Kubica J, et al. Personalized antiplatelet therapy with P2Y12 receptor inhibitors: benefits and pitfalls. Postepy Kardio Interwencyjnej. 2015; 11(4): 259-280, doi: 10.5114/pwki.2015.55596, indexed in Pubmed: 26677375.

6. Stewart K, Mc Namara KP, George J. Challenges in measuring medication adherence: experiences from a controlled trial. Int J Clin Pharm. 2014; 36(1): 15-19, doi: 10.1007/s11096-013-9877-6, indexed in Pubmed: 24293282.

7. Kubica A, Sinkiewicz W, Szymański P, et al. Edukacja zdrowotna w chorobach układu krążenia - możliwości i zagrożenia. Folia Cardiologica Excerpta. 2007; 2: 177

8. Kubica A. Wybrane problemy prewencji wtórnej u chorych po incydentach wieńcowych. Folia Cardiologica Excerpta. 2008; 3: 366

9. Kubica A, Obońska K, Kasprzak M, et al. The impact of metabolic syndrome on the antiplatelet effect of clopidogrel and aspirin in patients with acute coronary syndrome. : Folia Med Copernicana 2014; 2: 66-72.

10. Kubica A, Kasprzak M, Obońska K, et al. Impact of health education on adherence to clopidogrel and clinical effectiveness of antiplatelet treatment in patients after myocardial infarction: Folia Med. Copernicana. 2015; 3: 154-159.
11. Kubica J, Jaguszewski M. ISAR-REACT 5 - What have we learned? Cardiol J. 2019; 26(5): 427-428, doi: 10.5603/CJ.a2019.0090, indexed in Pubmed: 31536136

12. Kubica A, Kasprzak M, Obońska K, et al. Discrepancies in assessment of adherence to antiplatelet treatment after myocardial infarction. Pharmacology. 2015; 95(1-2): 50-58, doi: 10.1159/000371392, indexed in Pubmed: 25592409

13. Vermeire $E$, Hearnshaw $H$, Van Royen $P$, et al. Patient adherence to treatment: three decades of research. A comprehensive review. J Clin Pharm Ther. 2001; 26(5): 331-342, doi: 10.1046/j.13652710.2001.00363x, indexed in Pubmed: 11679023.

14. Zhao $\mathrm{S}$, Zhao $\mathrm{H}$, Wang $\mathrm{L}$, et al. Education is critical for medication adherence in patients with coronary heart disease. Acta Cardiol. 2015; 70(2): 197-204, doi: 10.1080/ac.70.2.3073511, indexed in Pubmed: 26148380

15. Polack J, Jorgenson D, Robertson P. Evaluation of different methods of providing medication-related education to patients following myocardial infarction. Canadian Pharmacists Journal. 2008; 141(4): 241-247, doi: 10.3821/1913-701x(2008)141[241:eodmop]2.0.co;2.

16. Kubica A, Pufal J, Moczulska B, et al. Skuteczność edukacji zdrowotnej u osób hospitalizowanych w klinice kardiologii. Psychiatria w Praktyce Ogólnolekarskiej. 2005; 5: 61.

17. Kubica A. Problems of long-term antiplatelet therapy after coronary stent implantation. Advances in Interventional Cardiology. 2009; 5: 158-161.

18. Kubica A, Grześk G, Sinkiewicz W, et al. Compliance, concordance, adherence in chronic therapy. Folia Cardiol Excerpta. 2010; 5: 54-57.

19. Buszko K, Obońska K, Michalski P, et al. The Adherence Scale in Chronic Diseases (ASCD). The power of knowledge: the key to successful patient - health care provider cooperation. Medical Research Journal. 2016; 1(1): 37-42, doi: 10.5603/mrj.2016.0006.

20. Kosobucka A, Michalski P, Pietrzykowski $\measuredangle$, et al. Adherence to treatment assessed with the Adherence in Chronic Diseases Scale in patients after myocardial infarction. Patient Prefer Adherence. 2018; 12: 333-340, doi: 10.2147/PPA.S150435, indexed in Pubmed: 29551891

21. Kosobucka A, Michalski P, Pietrzykowski $Ł$, et al. The impact of readiness to discharge from hospital on adherence to treatment in patients after myocardial infarction. Cardiol J. 2020 [Epub ahead of print], doi: 10.5603/CJ.a2020.0005, indexed in Pubmed: 32037501.

22. Pietrzykowski $Ł$, Michalski P, Kosobucka A, et al. Medication adherence and its determinants in patients after myocardial infarction. Sci Rep. 2020; 10(1): 12028, doi: 10.1038/s41598-020-68915-1, indexed in Pubmed: 32694522

23. Kubica A, Kosobucka A, Michalski P, et al. The Adherence in Chronic Diseases Scale - a new tool to monitor implementation of a treatment plan. Folia Cardiologica 2017;12:19-26, DOI: 10. 5603/FC. ; 2016: 0000, doi: 10.5603/FC.2016.0000.

24. Kubica A, Kochman W, Bogdan M, et al. The influence of undergone percutaneous coronary interventions, and earlier hospitalizations with myocardial infarction on the level of knowledge and the effectiveness of health education in patients with myocardial infarction. Advances in Interventional Cardiology. 2009; 5: 25-30.

25. DiMatteo MR. Variations in patients' adherence to medical recommendations: a quantitative review of 50 years of research. Med Care. 2004; 42(3): 200-209, doi: 10.1097/01.mlr.0000114908.90348.f9, indexed in Pubmed: 15076819.

26. Tang L, Patao C, Chuang J, et al. Cardiovascular risk factor control and adherence to recommended lifestyle and medical therapies in persons with coronary heart disease (from the National Health and Nutrition Examination Survey 2007-2010). Am J Cardiol. 2013; 112(8): 1126-1132, doi: 10.1016/j.amjcard.2013.05.064, indexed in Pubmed: 23827404.

27. Kubica A, Obońska K, Fabiszak T, et al. Adherence to antiplatelet treatment with P2Y12 receptor inhibitors. Is there anything we can do to improve it? A systematic review of randomized trials. Curr Med Res Opin. 2016; 32(8): 1441-1451, doi: 10.1080/03007995.2016.1182901, indexed in Pubmed: 27112628.

28. Kubica A, Kasprzak M, Siller-Matula J, et al. Time-related changes in determinants of antiplatelet effect of clopidogrel in patients after myocardial infarction. Eur J Pharmacol. 2014; 742: 47-54, doi: 10.1016/j. ejphar.2014.08.009, indexed in Pubmed: 25199965.

29. Kubica A, Obońska K, Kasprzak M, et al. Prediction of high risk of non-adherence to antiplatelet treatment. Kardiol Pol. 2016; 74(1): 61-67, doi: 10.5603/KP.a2015.0117, indexed in Pubmed: 26101025.

30. Wang PS, Benner JS, Glynn RJ, et al. How well do patients report noncompliance with antihypertensive medications?: a comparison of self-report versus filled prescriptions. Pharmacoepidemiol Drug Saf. 2004; 13(1): 11-19, doi: 10.1002/pds.819, indexed in Pubmed: 14971118. 
31. Frost MH, Reeve BB, Liepa AM, et al. Mayo/FDA Patient-Reported Outcomes Consensus Meeting Group;. What is sufficient evidence for the reliability and validity of patient-reported outcome measures? Value Health. 2007; 10 Suppl 2: S94-S9S105, doi: 10.1111/j.15244733.2007.00272.x, indexed in Pubmed: 17995479

32. Krousel-Wood M, Muntner P, Jannu A, et al. Reliability of a medication adherence measure in an outpatient setting. Am J Med Sci. 2005; 330: 128-133.

33. Kubica A. Collaboration with the patient - a basic condition of therapy effectiveness in coronary artery disease. Chor. Serca Nacz. 2009; 6: 131-134

34. Ho PM, Spertus JA, Masoudi FA, et al. Impact of medication therapy discontinuation on mortality after myocardial infarction. Arch Intern Med. 2006; 166(17): 1842-1847, doi: 10.1001/archinte.166.17.1842, indexed in Pubmed: 17000940.

35. Valgimigli M, Bueno $H$, Byrne RA, et al. ESC Scientific Document Group, ESC Committee for Practice Guidelines (CPG), ESC National Cardiac Societies. 2017 ESC focused update on dual antiplatelet therapy in coronary artery disease developed in collaboration with EACTS: The Task Force for dual antiplatelet therapy in coronary artery disease of the European Society of Cardiology (ESC) and of the European Association for Cardio-Thoracic Surgery (EACTS). Eur Heart J. 2018; 39(3): 213-260, doi: 10.1093/eurheartj/ehx419, indexed in Pubmed: 28886622.

36. Kubica J, Adamski P, Niezgoda P, et al. Prolonged antithrombotic therapy in patients after acute coronary syndrome: A critical appraisal of current European Society of Cardiology guidelines. Cardiol J. 2020 [Epub ahead of print], doi: 10.5603/CJ.a2020.0132, indexed in Pubmed: 33073857

37. Adamski $P$, Adamska U, Ostrowska $M$, et al. New directions for pharmacotherapy in the treatment of acute coronary syndrome. Expert Opin Pharmacother. 2016; 17(17): 2291-2306, doi: 10.1080/14656566.2016.1241234, indexed in Pubmed: 27677394

38. Kubica A. Self-reported questionnaires for a comprehensive assessment of patients after acute coronary syndrome. Medical Research Journal. 2019; 4(2): 106-109, doi: 10.5603/MRJ.a2019.0021.

39. Michalski P, Kasprzak M, Siedlaczek M, et al. The impact of knowledge and effectiveness of educational intervention on readiness for hospital discharge and adherence to therapeutic recommendations in patients with acute coronary syndrome. Medical Research Journal. 2020, doi: 10.5603/mrj.a2020.0023.

40. Kubica A. Rationale of cardiopulmonary resuscitation training as an element of multilevel educational and motivational project (MEDMOTION). Disaster and Emergency Medicine Journal. 2020, doi: 10.5603/demj.a2020.0017.

41. Kubica A, Bączkowska A. Uzasadnienie interwencji motywacyjnych jako kluczowego elementu projektu wielopoziomowej edukacji i motywacji u pacjentów z zawałem serca (MEDMOTION). Folia Cardiologica. 2020; 15(1): 6-10, doi: 10.5603/fc.2020.0003

42. Buszko K, Pietrzykowski $Ł$, Michalski P, et al. Validation of the Functioning in Chronic Illness Scale (FCIS). Medical Research Journal. 2018; 3(2): 63-69, doi: 10.5603/mrj.2018.0011.

43. Pietrzykowski $Ł$, Michalski P, Kosobucka A, et al. Knowledge about health and disease in obese patients after myocardial infarction. An observational study. Medical Research Journal. 2018; 2(4): 135-140, doi: 10.5603/mrj.2017.0018.

44. Kubica A, Kosobucka A, Michalski P, et al. Self-reported questionnaires for assessment adherence to treatment in patients with cardiovascu- lar diseases. Medical Research Journal. 2018; 2(4): 115-122, doi: 10.5603/mrj.2017.0015.

45. Kubica A, Gruchała M, Jaguszewski M, et al. Adherence to treatment - a pivotal issue in long-term treatment of patients with cardiovascular diseases. An expert standpoint. Medical Research Journal 2017;2(4):123-127. DOI: 10 5603/MRJ. ; 2017: 0016, doi: 10.5603/MRJ.2017.0016.

46. Kosobucka A, Kasprzak M, Michalski P, et al. Relation of the Readiness for Hospital Discharge after Myocardial Infarction Scale to socio-demographic and clinical factors. An observational study. Medical Research Journal 2018:3(1):32-37. DOI: 10 5603/MRJ. ; 2018: 0006, doi: 10.5603/MRJ.2018.0006

47. Michalski P, Kosobucka A, Pietrzykowski $Ł$, et al. Effectiveness of therapeutic education in patients with myocardial infarction. Medical Research Journal. 2018; 2(3): 89-96, doi: 10.5603/mrj.2017.0011.

48. Buszko K, Kosobucka A, Michalski P, et al. The readiness for hospital discharge of patients after acute myocardial infarction: a new self-reported questionnaire. Medical Research Journal. 2017; 2(1): 20-28, doi: 10.5603/mrj.2017.0004.

49. Miller WR. Motivational interviewing with problem drinkers. Behavioural Psychotherapy. 2009; 11(2): 147-172, doi: 10. ; 1017: s0141347300006583

50. Miller W, Rollnick S. Motivational Interviewing: Preparing People for Change, 2nd ed. Journal For Healthcare Quality. 2003; 25(3): 46, doi: 10.1097/01445442-200305000-00013

51. Hardcastle S, Taylor A, Bailey M, et al. A randomised controlled trial on the effectiveness of a primary health care based counselling intervention on physical activity, diet and $\mathrm{CHD}$ risk factors. Patient Educ Couns. 2008; 70(1): 31-39, doi: 10.1016/j.pec.2007.09.014, indexed in Pubmed: 17997263.

52. Hardcastle SJ, Taylor AH, Bailey MP, et al. Effectiveness of a motivational interviewing intervention on weight loss, physical activity and cardiovascular disease risk factors: a randomised controlled trial with a 12-month post-intervention follow-up. Int J Behav Nutr Phys Act. 2013; 10: 40, doi: 10.1186/1479-5868-10-40, indexed in Pubmed: 23537492.

53. Garbers S, Hunersen K, Nechitilo M, et al. Healthy Weight and Cardiovascular Health Promotion Interventions for Adolescent and Young Adult Males of Color: A Systematic Review. Am J Mens Health. 2018; 12(5): 1328-1351, doi: 10.1177/1557988318777923, indexed in Pubmed: 29808765

54. Gianos E, Schoenthaler A, et al. Guo Yu, Investigation of motivational interviewing and prevention consults to achieve cardiovascular targets (IMPACT) trial. Am Heart J. 2018; 199: 37-43, doi: 10.1016/j. ahi.2017.12. 019, indexed in Pubmed. : 29754664, doi: 10.1016/j.

55. Ringen PA, Falk RS, Antonsen B, et al. Using motivational techniques to reduce cardiometabolic risk factors in long term psychiatric inpatients: a naturalistic interventional study. BMC Psychiatry. 2018; 18(1): 255 , doi: 10.1186/s12888-018-1832-6, indexed in Pubmed: 30111298.

56. Heckman CJ, Egleston BL, Hofmann MT. Efficacy of motivational interviewing for smoking cessation: a systematic review and meta-analysis. Tob Control. 2010; 19(5): 410-416, doi: 10.1136/tc.2009.033175, indexed in Pubmed: 20675688

57. Dobber J, Latour C, de Haan L, et al. Medication adherence in patients with schizophrenia: a qualitative study of the patient process in motivational interviewing. BMC Psychiatry. 2018; 18(1): 135, doi: 10.1186/s12888-018-1724-9, indexed in Pubmed: 29776393.

58. Miller WR, Rollnick S. Motivational Interviewing: preparing people for change. 2nd ed. Guilford Press, New York. ; 2002. 